\title{
PERKEMBANGAN INFORMASI TEKNOLOGI DALAM KOMUNIKASI ANTAR BUDAYA
}

\author{
Muhammad Zidan Surya Pratama \\ Ilmu Komunikasi, FISIP, Universitas Sultan Ageng Tirtayasa \\ zidanprtm23@gmail.com
}

\begin{abstract}
Abstrak
Di era informasi, segalanya berjalan sendiri dengan murah, kilat, pas, serta akurat. Teknologi komunikasi disaat ini menghasilkan apa yang dituturkan publik dunia. Pertumbuhan teknologi komunikasi tidak bisa dipisahkan dalam kehidupan manusia. Ditambah dengan pertumbuhan internet, media komunikasi yang erat hubungannya dengan manusia. Manusia lebih gampang berhubungan satu sama lain. Media sosial tumbuh guna menanggapi kebutuhan dan mengarah pada transformasi proses komunikasi antar manusia. Tidak terkecuali komunikasi lintas budaya pula memasuki masa baru. Komunikasi Lintas Budaya tumbuh dengan timbulnya teknologi komunikasi. Media internet yang menghubungkan budaya orang yang berbeda, bahasa yang berbeda, bukti diri, pemikiran hidup modul agama, bisa melaksanakan komunikasi dengan gampang. Timbulnya internet serta komunikasi siber jadi media komunikasi Lintas Budaya, sehingga tidak bisa dipungkiri dalam aplikasi komunikasi Lintas Budaya menghasilkan suatu komunitas cyber baru yakni antarbudaya.
\end{abstract}

Kata Kunci: Teknologi, Budaya dan Komunikasi

\begin{abstract}
In the information age, everything goes by itself cheaply, quickly, precisely, and accurately. Today's communication technology produces what is spoken by the world's public. The growth of communication technology can not be separated from human life. Coupled with the growth of the internet, a communication medium that is closely related to humans. Humans are easier to relate to each other. Social media grows to respond to needs and leads to the transformation of the communication process between people. No exception cross-cultural communication also entered a new era. Cross-Cultural Communication grows with the emergence of communication technology. Internet media that connects different people's cultures, different languages, self-evidence, life thoughts, religious modules, can carry out communication easily. The emergence of the internet and cyber communication has become a medium of cross-cultural communication, so it cannot be denied that the application of cross-cultural communication produces a new cyber community, namely intercultural.
\end{abstract}

Keywords: Technology, Culture, and Communication 
Pada saat ini komunikasi ialah perihal yang sangat bernilai dalam interaksi sosial, kebutuhan manusia selaku mahluk social membawa manusia pada suasana komunikasi guna bermacam tujuan, aktualisasi diri, berbagi informasi, tamasya apalagi buat kepentingan- kepentingan sosial yang lain. Realitas jika manusia hidup di tengah- tengah situasi sosial serta budaya yang berbeda dengan orang lain hingga munculnya gesekan sosial akibat perbandingan interpretasi sangat memungkinkan.

Keragaman budaya dalam interaksi social mempunyai kompleksitas yang luar biasa. Serupa 2 sisi mata uang antara keuntungan serta kerugian merupakan perihal wajar dalam jalinan sosial. Pertumbuhan komunikasi antarbudaya secara keilmuan lumayan pesat bakal tapi pada tataran praktis masih memunculkan banyak perkara, karna bagaimanapun tidak mudah buat membandingkan serta mendesak orang yang berbeda budaya guna menerima serta menguasai budaya yang lain.

Sehingga sesungguhnya kesempatan melaksanakan komunikasi antarbudaya serta komunikasi lintasbudaya lewat media begitu sangat besar. Hingga dari itu tulisan ini hendak fokus pada bagaimana komunikasi antarbudaya dalam pertumbuhan data serta teknologi, dengan menggunakan media internet selaku bagian dalam proses komunikasi antarbudaya sehingga menghasilkan ruang baru dalam media antarbudaya yaitu komunitas cybercommunity yang aktif melaksanakan komunikasi antarbudaya.

\section{PEMBAHASAN}

Dari seluruh aspek manusia belajar, komunikasi ialah aspek terutama serta sangat mendasar. Dalam sesuatu kehidupan sosial, komunikasi jadi suatu yang berarti. Ikatan antara manusia yang satu dengan yang yang lain dalam interaksi pada komunitas warga majemuk terjalin melalui kegiatan komunikasi antarbudaya. Komunikasi antarbudaya ialah aktivitas komunikasi antarpribadi yang berlangsung diantara orang- orang yang berbeda latar belakang budaya. 2 konsep yang terpaut dengan komunikasi antarbudaya merupakan konsep kebudayaan serta konsep komunikasi dan juga komunikasi antarbudaya bisa disebut yang mencakup makna universal serta menampilkan pada komunikasi antara orang- orang yang memiliki latar belakang kebudayaan yang berbeda.

Pesan dalam komunikasi antarbudaya ialah simbol- simbol yang di dalamnya tercantum karateristik komunikasi yang terdengar ataupun nampak dalam pengalaman proses komunikasi antarpribadi di antara mereka yang berbeda etniknya. Bahasa mencerminkan budaya. Kian besar perbandingan budaya, kian besar perbandingan komunikasi baik dalam bahasa ataupun dalam isyarat- isya rat nonverbal. Kian besar perbandingan antara budaya kian susah komunikasi dilakukan.

Jaringan internet tidak cuma digunakan buat mengakses bermacam informasi akn tetapi pula ialah media social guna melaksanakan interaksi. Kala orang berada di depan perangkat computer yang tersambung dengan internet seakan terletak di belahan dunia lain. Menempuh kehidupan disitu secara temporer. Kala dia mematikan internetnya, seakan ia kembali ke" dunianya". Sayling Wen( 2001) berkata jika saat ini ini yang terutama serta sangat luas merupakan internet, yang menghubungkan komputer- komputer individu yang sangat simpel sampai yang luar biasa mutakhir.

Internet disaat ini sudah tumbuh sedemikian rupa jadi suatu teknologi yang sanggup menghasilkan dunia baru dalam kenyataan kehidupan manusia dengan keahlian internet dalam menghasilkan ruang maya yang amat kilat dalam kehidupan nyata, hingga seorang pada saat berselancar di internet bukan lagi tengah“ menggunakan" internet sebagai teknologi, tetapi“ menggunakan" internet serupa 
bagian dari kehidupannya. Contoh yang gampang yaitu misalkan pada video conference, sasaran ataupun lawan bicara kita tidak terdapat di ruang serta waktu yang sama dengan kita, namun internet sanggup memperkenalkan citranya dengan seluruh kelengkapannya di layar monitor kita sehingga seakan kita merasa kalau lawan bicara kita terdapat bersama kita. Contoh yang gampang yaitu disaat ini kita dapat berjumpa dengan kerabat yang sangat jauh hanya dengan menggenggam smartphone, tidak cuma mendengar suaranya namun kita dapat memandang sepenuhnya, beda dengan era dulu saat sebelum adanya internet yang dimana bila kita mau berjumpa dengan kerabat jauh maka kita mesti pergi ke tempat tersebut.

Menurut Martin dan Nakayama (1997), ada tiga pendekatan dalam mempelajari komunikasi antarbudaya. Pertama, pendekatan fungsional yang menyatakan pada dasarnya kebiasaan manusia itu dapat diketahui melalui penampilan luar dan dapat digambarkan. Kedua, pendekatan interpretatif yang menegaskan pada dasarnya manusia itu mengonstruksi dirinya dan realitas yang berada di luar dirinya. Pendekatan ini meyakini bahwa budaya dan komunikasi bersifat subjektif. Ketiga, pendekatan kritis. Pendekatan ini tidak sekadar mempelajari kebiasaan manusia, tetapi dengan mempelajari bagaimana kekuasaan sosial atau politik berfungsi dalam situasi budaya tertentu akan memberikan solusi pada manusia dalam menyikapi kekuasaan. Tetapi patut dicatat, teknologi data bukanlah serta merta mengganti kultur yang terdapat di tengah warga serta apabila terdapat pergantian kultur juga diakibatkan oleh interaksi yang terjalin di antara keduanya. Intinya, pertumbuhan serta perkembangan internet berusia ini sudah mengganti wajah dunia. Terdapat banyak perihal yang berganti. Bermacam perihal yang sebelumnya terbatas oleh keadaan serta geografis saat ini lama- lama mengabur, menjadikan pertukaran data berlangsung selama waktu. Tetapi di sisi lain, keadaan ini pula terus menjadi mengaburkan batas antarbudaya, mengganti metode berbicara antarbudaya, serta secara langsung ataupun tidak langsung memperkenalkan percampuran budaya.

\section{KESIMPULAN}

Pertumbuhan media data serta timbulnya media- media sosial dalam bermacam wujudnya membuat pergantian yang radikal dalam keadaan sosial warga disaat ini. Pola komunikasi berganti jadi pola komunikasi maya serta virtual. Interaksi yang terjalin ialah simulasi simulasi dari kenyataan yang sesungguhnya. Keberadaan bermacam fitur dalam smartphone ko- munikator semakin mempermudah warga dalam pola komunikasi visual dengan media. Dalam interaksi sosial orang menekuni simbol- simbol yang membolehkan dalam menjalakan ikatan serta komunikasi. Pemaknaan terhadap simbol- simbol ini membolehkan orang melakukan aksi serta interaksi unik antara manusia yang satu serta yang lain.

Pada kesimpulannya media internet mejadi media antarbudaya yang sangat strategis dan sangat mudah secara fungsional membagikan informasi budaya, bahasa, symbol religi dari tiap- tiap anggota budaya yang dipertukarkan lewat komunikasi media internet. Chat, berkirim pesan pendek pada facebook, messenger serta aplikasi yang lain memeberikan ruang serta menghasilkan pola tertentu dalam komunikasi antarbudaya.

\section{DAFTAR PUSTAKA}

Ainiyah, N. (2016). Komunikasi dan Media Antarbudaya: Formulasi Komunikasi Antarbudaya Dalam Perkembangan Informasi Teknologi. Al'Adalah, 18(2). 
Holmes, D. (2012). Teori Komunikasi: Media, Teknologi dan Masyarakat. Yogyakarta: Pustaka Pelajar.

Liliweri, Alo. (2002). Makna Budaya dalam Komunikasi Antarbudaya. Jogjakarta: LKIS. 